\title{
Comparing the Distribution of Education Across the Developing World, 1960-2005: What Does the Grade Enrollment Distribution Tell about Latin America?
}

\author{
Ewout Frankema
}

Accepted: 23 October 2007 / Published online: 24 January 2008

(C) The Author(s) 2008

\begin{abstract}
The present paper introduces a new indicator of educational inequality, the grade distribution ratio (GDR), focusing on levels of grade repetition and drop out rates in primary and secondary education. The indicator is specifically suitable to evaluate the distributive implications of expanding educational systems in developing countries. A comparative analysis of grade enrollment distributions across 92 developing countries from 1960 to 2005 reveals that the decline in educational inequality has been substantial and wide spread since 1960, but that progress has slowed down in the last two decades. Latin American countries were characterized by very large initial levels of educational inequality, but contrary to other developing regions continued to equalize their grade enrollment distribution in the last two decades.
\end{abstract}

Keywords Grade enrollment distribution · Educational inequality · Latin America

\section{Introduction}

Reducing inequality in access to schooling is a major concern in the developing world. Since the second half of the 20th century, the number of countries that have accomplished full primary school enrollment has increased dramatically. However, the characteristics of the recently developed and expanded educational systems vary greatly across developing countries. Some have been highly successful in the implementation of educational programs reaching out to all layers of society and, partly as a result of these efforts, are no longer considered a developing country. In other countries improvement has been much slower. Even in cases where the objective of full primary school enrollment has been accomplished, actual school attendance and educational participation often remains highly unequal as between the rich children of the rich and the poor.

E. Frankema $(\bowtie)$

Department of Economics, University of Groningen, Landleven 5, Groningen 9700 AV,

The Netherlands

e-mail: e.h.p.frankema@rug.nl 
The objective of this paper is to assess and compare the distribution of education across the developing world using a new indicator, the grade distribution ratio (GDR). The GDR contains information on levels of grade repetition and drop out rates which can be used to evaluate the distributive implications and effectiveness of national educational systems in terms of grade promotion and school completion. It is argued that specifically for countries with relatively confined data sources to analyze educational inequality, the GDR resolves a gap: a gap between the rather comprehensive, yet severely biased educational Gini-coefficient, the rather superficial (from a distributional perspective at least) indicators such as school enrollment and literacy rates, and the more recently developed and advanced measures of school performance, which still remain largely confined to OECD countries and also lack historical benchmark levels.

The GDR is estimated and compared across a sample of 92 developing countries with five decadal observations in the period 1960-2005. The main conclusions are that over the period 1960-2005 levels of educational inequality have declined substantially, but that progress has slowed down in most regions in the last two decades. Latin American countries form the exception to the rule. Starting out with very high levels of educational inequality, they have rapidly caught up with other developing countries, particularly during the 1990s.

Section 2 will start with a discussion of the literature on educational inequality and builds the case for the grade enrollment distribution approach. Section 3 introduces the GDR and discusses the underlying concept of educational inequality. Section 4 presents, analyses and compares the GDR estimates. Section 5 contains a more in-depth analysis of the shape and slope of the grade enrollment distribution in Latin American countries and a selection of non-Latin American countries. Section 6 concludes.

\section{Concepts and Indicators of Educational Inequality}

Contrary to income distribution studies using Gini- or Theil coefficients as a comprehensive measure of income inequality, empirical studies on the distribution of education employ a broad set of partial indicators to assess various dimensions of educational inequality. Primary school enrollment rates and literacy rates are the two most basic indicators of educational development and educational distribution alike. These indicators reveal the gap between children who have (had) the opportunity to go to school and those who haven't (had) (Clemens 2004). With the on-going spread of elementary education in the developing world the informative power of these indicators diminishes, fortunately.

A crude, yet appealingly simple, measure of educational distribution is the percentage share of children that completes secondary schooling. This indicator (which can also be taken from educational attainment data) is considered to reflect the extent of the "middle-class" in education (Nehru et al. 1995; Birdsall et al. 1997). For developing countries this indicator is not very informative however, since a low percentage share of secondary school completion does not necessarily reflect inequality in the distribution of education: the share could be zero, while participation in primary education is perfectly egalitarian.

The estimation of educational expenditure per student and level of education and the number of students per teacher per level of education, provide insight into the educational priorities set by the public administration or society as a whole. These educational input indicators contain valuable information on the distribution of public educational 
resources. The expenditure distribution has, for example, been used to show the contrast between the high relative levels of expenditure on tertiary education in Latin America, with the priorities of East Asian NIE's in primary education investments (Birdsall and Sabot 1994; Birdsall et al. 1997). One of the disadvantages of working with this type of data is that the expenditure concepts and different sources (state, municipality, private) of educational investment are often incompatible for a fruitful comparison between countries. For a lot of developing countries the data are highly problematic, if available at all (Lindert 2004).

With the introduction of educational stock estimates based on the years of attainment of the working age population (Psacharapoulos and Arriagada 1986; Nehru et al. 1995; Barro and Lee 1993, 2001) it has become possible to estimate indicators such as the standard deviation (Ram 1990; Birdsall 1999) and the Gini-coefficient of attainment (Thomas et al. 2001; Castello and Domenech 2002; Sahn and Younger 2004). These studies have provided new perspectives on educational inequality. Moreover, the increasing availability of student test results in literacy and math have made it possible to measure the distribution of student's educational performance within and between countries, which provides a much better approximation of qualitative educational output, compared to "years of schooling" type of data (OECD 2001, 2004, 2006).

Yet, despite these promising trends in data collection there still is a good case for broadening the scope, in particular since recent advances in literature fail to accurately incorporate developing countries. The measures of student's test performances have, so far, been largely confined to OECD countries and lack the possibility of historical benchmarking. The Gini-coefficient of years of schooling attained, however appealing as a comprehensive distributive indicator, is problematic for other reasons. This indicator is highly sensitive to the percentage share of the population that has received no schooling at all, a category especially relevant for developing countries. The correlation coefficient between the Gini and the share of the working age population without schooling is 0.96 (estimated with attainment data from Barro and Lee 2001: see Frankema and Bolt 2006).

The bias in the Gini towards one specific dimension of educational inequality, i.e. the gap between those who have and those who have not attained schooling, basically makes this indicator a close substitute for primary school enrollment rates. The use of the Gini could therefore be better restricted to a comparative analysis of OECD countries (where the no-schooling category is virtually zero), although it should be noted that even then the Gini remains sensitive to the characteristics of the bottom category in the attainment distribution. The estimated correlation between the Gini and the average years of attainment is 0.96, and when average attainment levels are held constant the variation around the regression line reveals heteroskedasticity (Frankema and Bolt 2006).

The grade distribution ratio introduced in this paper is, of course, not a perfect indicator either. The GDR captures the effects of irregular school attendance (absenteeism) and a suboptimal learning environment on the levels of grade repetition and pre-completion drop out rates. This helps to understand under which conditions the expansion of school enrollment takes place. Obviously, this type of distributive information is particularly valuable in the context of developing countries, but provides less insight into the distributive details of more developed educational systems. In this sense the GDR is "yet another partial indicator". The great advantage of the grade enrollment distribution approach is, however, that it enables the inclusion of a large group of countries for which educational data are generally rather poor, that it provides a rather simple and straightforward standardized measure of inequality and still captures a reasonable amount of detailed information on such crucial aspects as grade promotion and school completion. 


\section{The Grade Enrollment Distribution Approach}

The percentage distribution of grade enrollment rates in primary and secondary schooling are available in the UNESCO Yearbook of Statistics for 5-year intervals from ca. 1960 onwards and are since 1999 accessible online (UNESCO Institute for Statistics (UIS)). The grade distributions of primary and secondary schooling can be linked together using the absolute number of pupils enrolled in both levels of schooling and weighing the independent percentage distributions according to the following formulas,

$$
\frac{X_{p}}{X_{p}+X_{s}} \times g_{p i}, \quad \frac{X_{s}}{X_{p}+X_{s}} \times g_{s i}
$$

where $X_{p}$ and $X_{s}$ refer to the number of students enrolled in respectively primary and secondary schooling and $g_{p i}$ and $g_{s i}$ refer to the percentage share of students enrolled in the $i$ th grade of respectively the primary and secondary school.

Depending on the total number of grades in primary and secondary education a standardized distribution can be obtained for 10-12 grades for 92 (former) developing countries (the sample we are working with in this paper) and 32 industrialized countries (Europe, New World and Japan). ${ }^{1}$ To illustrate some of the variety in the data, Table 1 presents the standardized grade enrollment distribution in Argentina and Canada for the year 1960.

In the hypothetical scenario that each grade contains exactly the same amount, all 12 grades would contain $100 / 12=8.33 \%$ of all pupils. In practice, the grade distribution is always skewed towards the lower grades because some children leave school earlier than others. Most OECD countries reveal a pattern comparable to Canada's, where the percentage shares decline more rapidly only in the final grades (9-12). At this point the first children have completed their secondary school. Developing countries reveal patterns that are more comparable to Argentina in 1960, or even far more skewed. Assuming, for the moment (we will discuss the validity of this assumption and possible solutions in paragraph 3.1 below), that the influx of new children in the system is constant, a considerable amount of children either repeat one or several of the lower grades for 1 or more years, or drop out before reaching the higher grades, or both.

Irregular school attendance goes a long way in explaining the phenomena of grade repetition and pre-completion drop out. Children may be officially enrolled (i.e. registered) without attending in practice. Absenteeism can have various causes that are mostly related to poverty: a lack of means to cover school expenses, a lack of school transportation and prohibitive distances to schools in rural areas, overcrowding of schools, health problems of the child (undernourishment), child labor, a lack of perceived interest of schooling by children's parents, a lack of support and attention by teachers, insufficient monitoring on attendance and performance, and so on and so forth.

The problem of grade repetition and dropping out has been recognized for a long time. In the 1956 report for the Brazilian Institute for Education, Science and Culture, composed by J.R. Moreira, it is shown that $53.1 \%$ of all Brazilian pupils are enrolled in the first grade, $21.8 \%$ in the second, $15.5 \%$ in the third and $9.7 \%$ in the final fourth grade. Moreover,

\footnotetext{
${ }^{1}$ In a few countries there is an overlap in the final grades of primary and the first grades of secondary schooling that requires extra calculations to link the series adequately. Generally the students in the "intermediate" grades were added to the first grades in secondary education. Occasionally the total number of grades in primary and secondary schooling exceeds twelve, in this case the distribution has been topped at the 12th grade and the number of students in higher grades is distracted from the denominator.
} 
Table 1 The percentage distribution of grade enrollment in Argentina and Canada in 1960, 12 consecutive grades in primary and secondary schooling

\begin{tabular}{|c|c|c|c|c|c|c|c|c|c|c|c|c|}
\hline Grade & 1 & 2 & 3 & 4 & 5 & 6 & 7 & 8 & 9 & 10 & 11 & 12 \\
\hline Argentina & 21.3 & 14.0 & 13.8 & 12.0 & 10.2 & 8.7 & 7.2 & 4.2 & 2.9 & 2.4 & 1.8 & 1.4 \\
\hline Canada & 11.9 & 11.1 & 10.8 & 10.3 & 10.0 & 9.7 & 9.3 & 8.4 & 7.1 & 5.1 & 3.8 & 2.4 \\
\hline
\end{tabular}

Source: UNESCO, Statistical Yearbook 1972, authors own calculations

$42.7 \%$ of the children leave school without ever passing the first grade and over $70 \%$ leaves school before completing 4 years of education. Out of the other $30 \%$ the majority of pupils spent 5, 6 or 7 years to finish four grades. The report states that,

"In a country which is obviously poor in spite of its present extraordinary industrial development, we fix something which is capable of change and revision, and keep the child in one primary grade for 2, 3 or more years or even turn him out of school before he has learnt the least it can give him." (UNESCO 1958, World Survey of Education II, p. 172).

The report is also remarkably frank about the possible causes of the ineffectiveness of the Brazilian educational system. The quality of the curriculum and the learning environment is criticized and the report also stresses the wide spread practice of child labor. The idea that education is beneficial for children was far self-evident,

"A school which is not felt to be absolutely necessary, because of its meagre curriculum, because the basic equipment for life which it gives its pupils is such a poor modicum, must inevitably be a school to which children only go if they have nothing more important to do." (UNESCO 1958, World Survey of Education II, p. 173)

And although primary education was legally compulsory and free of charge according to Brazil's 1946 constitution, the resources to meet these conditions were nowhere near. In rural areas schools were very thinly spread. In urban areas the schools were overcrowded. Due to a chronic shortage of school buildings, teachers and teacher materials there were multiple daily sessions in the cities. Referring to the poor states in the North East of the country the report is devastating,

“...retardation in the primary schools reaches alarming proportions, expanding and enlarging the school age band, multiplying the first grades, crowding the classroom, and dividing the school periods into two, three, or even four sessions because there are not enough funds to build more schools." (UNESCO 1958, World Survey of Education II, p. 172)

These observations make clear that the grade distribution not only contains important distributive information, but also captures aspects of the effectiveness of the educational system as such.

To place the picture of Brazil in a comparative perspective Fig. 1 presents the grade distribution of Colombia, Ghana, South Korea and Syria in 1970. For the interpretation of these graphs it is important to know that in Colombia the reported gross primary school enrollment rate in 1970 is 102\%, in Ghana 58\%, in South Korea 104\% and in Syria 88\% (UNESCO, Statistical Yearbook 1974).

The grade distribution in South Korea shows why the country is a model-country of educational expansion: its remarkably fast expansion in enrollment rates has been 

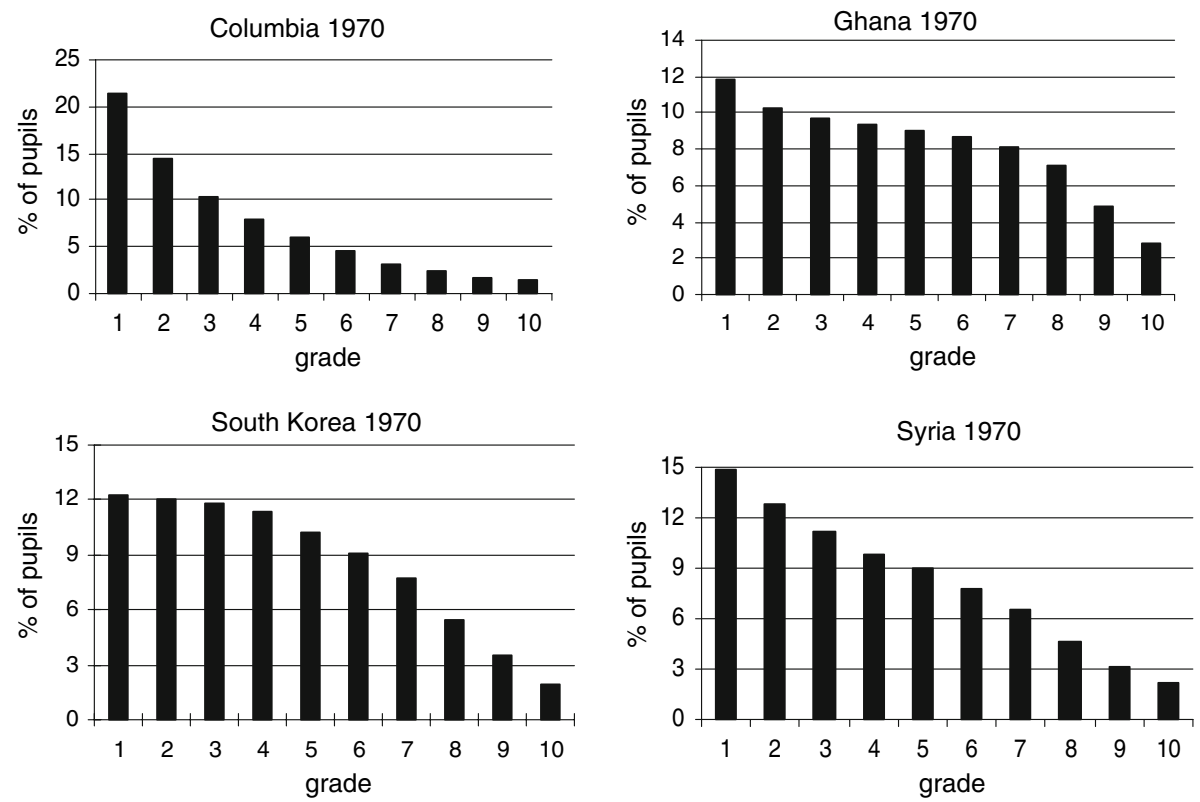

Fig. 1 Percentage distribution of grade enrollment in Colombia, Ghana, South Korea and Syria, 1970. Source: UNESCO, Statistical Yearbook, various issues, 1972-1980. Note: 3 years moving average of 12 consecutive grades in primary and secondary schooling

combined with a system that gives children a fair chance of grade promotion and school completion (World Bank 1993; Park et al. 1996). The concave trend of the graph indicates that the Korean children were rather evenly distributed among the grades in primary schooling, however less so in secondary schooling. A similar trend can be observed in Ghana up to the 1970s. Unfortunately, the progress towards full enrollment rates in Ghana has been on the reverse since the 1980s, when the development of the educational system became burdened by recurrent periods of political and economic instability.

Colombia's grade distribution closely resembles the Brazilian in this period. It reveals a convex trend signaling high rates of grade repetition and pre-completion drop out rates. In spite of full enrollment rates, Columbian primary schools coped with high levels of inequality in the distribution of education. Only a confined group of children completed primary schooling and enrolled into secondary schooling. Meanwhile, children enrolling in secondary education had a relatively large chance of finishing it compared to children in primary school.

Finally, the grade distribution of Syria exemplifies the "intermediate" case: it does not reveal an obvious convex or concave trend. There was a considerable level of inequality in the distribution of grade enrollment shares given the steep downward slope of the graph, but obviously less pronounced than in Colombia.

The crucial question is whether it is possible to frame the information in the grade distribution into a standardized indicator and compare this information across countries and over time. Which concept of educational inequality would be appropriate? A possibility is to estimate the probability that pupils entering school will have a smooth schoolcareer up to completion of either primary or secondary schooling. Therefore we may compare the total percentage share of students in grade 1 with the shares in grade 6,9 or 
12. The disadvantage of this approach, however, is that such a comparison is sensitive to year-to-year fluctuations that occasionally occur in school enrollment. A better strategy is to average out these fluctuations by taking a weighted measure of students enrolled in more than one grade. This will also reveal a larger part of the underlying structure of the distribution. Any ratio of grade enrollment rates is feasible once we normalize the equation for the number of grades involved as follows,

$$
\text { GDR } 1-N=\frac{\sum_{i=(n+1), N} g_{i}}{\sum_{i=1, n} g_{i}} \times \frac{n}{N-n}
$$

where $N$ is the total number of grades and $g_{i}$ is the percentage share of enrolled in the $i$ th grade. Since the majority of countries has adopted a six grade elementary curriculum a measure including the first six grades gives the best fit to standardize the inequality indicator for primary schools. Assuming that the influx of pupils is constant over time, the ratio of the grades 4-6 over 1-3 expresses the chance that a pupil in grades 1-3 reaches the higher grades $4-6$ without repeating grades or dropping out. Given Eq. 2, the GDR 1-6 is defined as,

$$
\text { GDR } 1-6=\frac{\sum_{i=4-6} g_{i}}{\sum_{i=1-3} g_{i}}
$$

This specification will be used in the cross-country analysis in Sect. 4.

\subsection{Adjusting for the Demographic Bias of the GDR}

The GDR may be influenced by factors that are not related to the functioning of the educational system per se. Various exogenous shocks such as war, natural disasters or economic crises may keep children at home for a shorter or longer time. This interruption of school attendance will skew the grade distribution and may cause considerable year-toyear fluctuations. If the interruption is of a temporary nature, children will return to school and as they catch up the effect on the distribution will eventually disappear. If the interruption is structural than the GDR will signal the impact of the disruption on the distribution of education and there is no need to correct for that, since it is part of what we want the GDR to capture.

The assumption that the influx of pupils is constant over time requires closer scrutiny however. The most important structural factor causing variation in school entrance rates is demographic change. A growing (or declining) school-age population skews the grade enrollment distribution, if it implies that each year more children enroll than in the previous year, other things equal. The countries under consideration here almost all witnessed rapid increases in their school-age populations (the 5-14 year old category) over the period 1960-2005. Demographic growth generally explains the bulk, between 75 and $100 \%$, of year-to-year fluctuations in total enrollment. It is necessary to know what are the potential effects on the GDR created by the demographic factor?

The demographic database of the UN provides population figures for the age group 5-14 from 1950 onwards (5-year intervals, see UN (World Population Prospects 2004)). For three regions and a group of least developed countries the average annual growth rates has been calculated for each decade. Table 2 shows the average annual growth rates 
Table 2 The effects of population growth on the grade distribution, annual growth of age group 5-14, 1960-2005

\begin{tabular}{|c|c|c|c|c|c|c|c|c|c|}
\hline & \multirow{2}{*}{$\begin{array}{l}\text { Annual growth } \\
\text { (age 5-14) } \\
1960-2005\end{array}$} & \multicolumn{6}{|c|}{ Grade distribution } & \multirow[t]{2}{*}{ GDR 1-6 } & \multirow[t]{2}{*}{ Distortion } \\
\hline & & 1 & 2 & 3 & 4 & 5 & 6 & & \\
\hline Africa & 0.026 & 11.4 & 11.1 & 10.8 & 10.5 & 10.3 & 10.0 & 0.926 & 0.074 \\
\hline Asia & 0.013 & 10.7 & 10.5 & 10.4 & 10.3 & 10.1 & 10.0 & 0.962 & 0.038 \\
\hline Latin America & 0.015 & 10.8 & 10.6 & 10.5 & 10.3 & 10.2 & 10.0 & 0.955 & 0.045 \\
\hline Least developed countries & 0.026 & 11.3 & 11.1 & 10.8 & 10.5 & 10.3 & 10.0 & 0.927 & 0.073 \\
\hline Latin America (1955-1965) & 0.034 & 11.8 & 11.4 & 11.1 & 10.7 & 10.3 & 10.0 & 0.905 & 0.095 \\
\hline
\end{tabular}

Source: Annual population growth figures taken from UN, Population Prospects 2004, medium variant. Other figures are based on authors own calculations

for the entire period 1960-2005 in Africa, Asia, Latin America and the least developed countries. To estimate the maximum possible impact of demographic change on the GDR 1-6, we also included Latin America in the decade 1955-1965 in the last row: the annual increase of the Latin American age cohort 5-14 at a rate of 3.4\% was the highest being encountered.

The outcome of this exercise is that, in the extreme case scenario, demographic growth can distort the GDR by almost 0.10 , ceteris paribus, and in some individual countries probably even slightly more. ${ }^{2}$ Clearly, the potential bias in the comparison of GDR's across countries and over time incurred by variation in demographic growth is considerable and needs to be corrected. Fortunately, the demographic data, i.e. the average annual decadal growth rates of the age cohort 5-14, required for adjusting the original GDR are readily available. By adding the estimated distortion (last column of Table 2) to the original GDR we obtain the adjusted GDR:

$$
\text { Adjusted } \mathrm{GDR}_{x i}=\text { original } \mathrm{GDR}_{x i}+\text { distortion }_{x i}
$$

where $x$ refers to the country and $i$ to the year of observation. To account for the time lag involved in the effect of changes in the influx of students on the GDR 1-6, the annual decadal growth rates were taken ca. 5 years in advance of the observation (depending on the exact year of observation of the original GDR). For example, the observation for South Korea in 1963 and Guatemala in 1961 are both adjusted for the average annual growth rate of the age cohort 5-14 over the years 1955-1964.

\section{The Grade Distribution Ratio in Developing Countries, 1960-2005}

Appendix Table A1 presents the original GDR 1-6 of 92 (former) developing countries and the regional averages of five regions for each decade in the period from 1960 to 2005. The five regions are South and West Asia, East Asia and the Pacific, Sub Saharan Africa, Latin America and North Africa and the Middle East. In addition to Table A1 some more details of the dataset are discussed.

\footnotetext{
${ }^{2}$ Given the variation around the Latin American mean (1955-1965). In many OECD countries the effect of declining birth rates results in a positive, albeit less substantial, bias.
} 


\subsection{The Slowdown of Equalization in the Grade Distribution}

Table 3 presents the regional averages of the GDR 1-6 derived from a fixed sample of 60 countries with a full coverage (each decade one observation) for the period 1960-2005. The first line of the table presents the ordinary arithmetic mean, the second presents the mean weighted for the share of each country in the total student population of the region and the third line presents the weighted and adjusted GDR's. Table 3 reveals several stylized facts of the distribution of primary education in the developing world from 1960 onwards. First, the grade distribution in primary schools has become considerably more equal in all five regions over time. The average increase ranges around $0.22-0.26$, with the exception of Latin America, which witnessed an overall increase of 0.42. It should be noted, however, that the initial levels of the Latin American GDR in 1960/1965 were remarkably low.

The second conclusion is that overall progress has recently come to a halt in four of the five regions. In East Asia there has been a significant set back and in Sub Saharan Africa the stagnation has set in already since the early 1980s. Latin America is the only region where the increase in the GDR between 1980 and 2005 has been very significant, by all standards. Although the "lost decade" of the 1980s has produced a temporary draw back in

Table 3 Interregional comparison of GDR's 1-6, arithmetic, weighted and weighted \& adjusted regional means, 1960-2005

\begin{tabular}{lllllll}
\hline & & $1960 / 1965$ & $1970 / 1975$ & $1980 / 1985$ & $1990 / 1995$ & $2000 / 2005$ \\
\hline South \& & Non weighted & 0.46 & 0.67 & 0.64 & 0.75 & 0.74 \\
West Asia (5) & Weighted & 0.42 & 0.50 & 0.53 & 0.68 & 0.72 \\
& Weighted \& adjusted & 0.50 & 0.57 & 0.58 & 0.73 & 0.74 \\
East Asia \& & Non weighted & 0.57 & 0.66 & 0.76 & 0.85 & 0.87 \\
Pacific (7) & Weighted & 0.54 & 0.64 & 0.69 & 0.93 & 0.88 \\
& Weighted \& adjusted & 0.62 & 0.72 & 0.72 & 0.93 & 0.87 \\
Latin America (19) & Non weighted & 0.41 & 0.57 & 0.68 & 0.74 & 0.84 \\
& Weighted & 0.33 & 0.49 & 0.59 & 0.66 & 0.85 \\
Sub Saharan & Weighted \& adjusted & 0.42 & 0.57 & 0.64 & 0.68 & 0.84 \\
Africa (19) & Non weighted & 0.50 & 0.64 & 0.69 & 0.72 & 0.68 \\
& Weighted & 0.51 & 0.59 & 0.71 & 0.72 & 0.68 \\
North Africa \& & Weighted \& adjusted & 0.59 & 0.67 & 0.79 & 0.80 & 0.75 \\
M. East (10) & Non weighted & 0.58 & 0.76 & 0.79 & 0.89 & 0.90 \\
& Weighted & 0.57 & 0.72 & 0.76 & 0.88 & 0.88 \\
\hline
\end{tabular}

Sources: Authors own calculations based on UNESCO, Statistical Yearbook, various issues 1966-1998 and UNESCO, Institute for Statistics, http://www.uis.unesco.org

Notes: Countries included are Afghanistan, Bahrain, Bangladesh, India and Iran (South \& West Asia); Hong Kong, Indonesia, South Korea, Laos, Malaysia, Philippines, Thailand (East Asia \& Pacific); Argentina, Bolivia, Brazil, Colombia, Costa Rica, Chile, Cuba, Ecuador, El Salvador, Guyana, Honduras, Mexico, Nicaragua, Panama, Paraguay, Peru, Trinidad \& Tobago, Uruguay, Venezuela (Latin America); Botswana, Burkina Faso, Congo Rep., Ethiopia, Gabon, The Gambia, Ghana, Ivory Coast, Kenya, Lesotho, Madagascar, Mauritania, Mauritius, Niger, Nigeria, Rwanda, Senegal, Uganda, Zambia (Sub Saharan Africa); Iraq, Israel, Jordan, Kuwait, Morocco, Qatar, Saudi Arabia, Syria, Tunisia, Turkey (North Africa \& Middle East) 
the steady increase of the GDR, this has been more than compensated for in the succeeding decade.

The recent stagnation may be largely explained by two factors. First, there has been a set back in some countries that weigh heavily in the regional means. In South and West Asia the mean is largely dominated by India, and although India had a net positive impact on the mean (compare the arithmetic and weighted mean) the increase of its GDR has been relatively small. Moreover, Afghanistan has witnessed a sharp decrease in its GDR in the last decade. The recent decline in Indonesia is largely responsible for the set back of the regional mean from 0.93 to 0.87 in East Asia. In North Africa and the Middle East contracting forces in Iraq have had a negative impact.

Apart from the developments in individual countries a more wide spread slowdown in the progress of the GDR 1-6 can be observed. This slowdown may signal decreasing marginal returns on efforts to equalize the grade distribution by means of supporting school attendance and preventing pre-completion drop out rates. It may also signal a reduced investment effort, apart from decreasing returns. In Sub Saharan Africa the effects of the growth disaster and continuous political instability since the 1980s are the most likely explanation for stagnation since the 1980s. The main point to take home from this analysis is that, although the developing world has made steady progress in improving and thereby equalizing the environment of children to attend school at a regular basis and finish primary school, there is still a long way to go. Present developments do not point in the right direction in all countries.

\subsection{The Choice between Enrollment and Attendance in Primary Education}

Post war educational expansion in developing countries can be considered as a combined effort to expand access to education per se and to raise school attendance, grade promotion and school completion to modern educational standards. There is, nevertheless, a huge cross-country variation in the combined accomplishment of both objectives: in some countries the expansion of access seems to have prevailed at the expense of attendance. In other countries the access barriers may have been removed (or are being removed) more gradually, yet those who enroll, do attend regularly. It is instructive to look at the variation in the GDR in the decade that a country reaches full primary school enrollment. Full enrollment is defined as a gross enrollment rate in primary education equal or above $0.95 .^{3}$

Table 4 lists 55 countries that have achieved full enrollment in the period 1960-2005 and the adjusted GDR's 1-6 in the decade they did so. The variation in GDR's is striking. In 1980, Jordan achieved full gross enrollment rates and grade enrollment equalization, whereas Brazil achieved full gross enrollment with an adjusted GDR of just 0.27. The same variety occurs when counting the number of decades that lie between full enrollment and a GDR surpassing the benchmark level of 0.95. In Malaysia, Singapore and Jordan no considerable time lag can be observed. South Korea, Cyprus and Mauritius needed one decade. On the other hand, it took Argentina five decades and Chile and Tunisia four decades to accomplish grade equalization. Panama, the Philippines and Uruguay are currently approaching a five-decade lag.

Table 4 shows that in particular Latin American countries have combined full enrollment rates with very low GDR's. The apparent Latin American strategy of educational

\footnotetext{
3 The "soft" benchmark of full enrollment allows for the confinement of gross enrollment observations to 5 -year intervals during which the final jump from 95 to $100+$ is often made.
} 
Table 4 Adjusted GDR 1-6 in the decade achieving full primary enrollment

\begin{tabular}{|c|c|c|c|c|c|c|c|c|c|}
\hline \multicolumn{2}{|l|}{$1960 \mathrm{~s}$} & \multicolumn{2}{|l|}{$1970 \mathrm{~s}$} & \multicolumn{2}{|l|}{$1980 \mathrm{~s}$} & \multicolumn{2}{|l|}{$1990 \mathrm{~s}$} & \multicolumn{2}{|l|}{$2000 / 2005$} \\
\hline Singapore & 1.00 & Mauritius & 0.87 & Jordan & 1.00 & Algeria & 0.92 & Tanzania & 0.84 \\
\hline Cyprus & 0.90 & Sri Lanka & 0.83 & Malaysia & 0.97 & Uganda & 0.68 & El Salvador & 0.73 \\
\hline Korea, Rep. & 0.83 & Zambia & 0.80 & Botswana & 0.90 & Bolivia & 0.68 & Benin & 0.65 \\
\hline Hong Kong & 0.79 & Qatar & 0.77 & Iraq & 0.84 & Gabon & 0.65 & Guatemala & 0.56 \\
\hline Philippines & 0.69 & Syria & 0.76 & Iran & 0.80 & Rwanda & 0.58 & & \\
\hline Panama & 0.66 & Swaziland & 0.72 & Thailand & 0.79 & Bangladesh & 0.56 & & \\
\hline Tunisia & 0.63 & Lesotho & 0.66 & Kenya & 0.75 & Nepal & 0.54 & & \\
\hline Uruguay & 0.61 & Peru & 0.65 & Kuwait & 0.70 & & & & \\
\hline Chile & 0.58 & Cameroon & 0.64 & Indonesia & 0.61 & & & & \\
\hline Turkey & 0.55 & Ecuador & 0.62 & India & 0.59 & & & & \\
\hline Costa Rica & 0.51 & Togo & 0.62 & Madagascar & 0.59 & & & & \\
\hline Congo, Rep. & 0.47 & Libya & 0.61 & Zimbabwe & 0.59 & & & & \\
\hline & & Mexico & 0.61 & Nigeria & 0.56 & & & & \\
\hline & & Vietnam & 0.54 & Honduras & 0.48 & & & & \\
\hline & & Myanmar & 0.47 & Laos & 0.43 & & & & \\
\hline & & Colombia & 0.45 & Brazil & 0.27 & & & & \\
\hline
\end{tabular}

Sources: UNESCO, Statistical Yearbook, various issues 1966-1998 and UNESCO, Institute for Statistics (UIS), http://www.uis.unseco.org. GDR's based on authors own calculations

Notes: Argentina, Israel and Trinidad \& Tobago are omitted since they achieved full primary enrollment rates in the 1940s and 1950s respectively

development can be described as one of "enrollment over attendance". Although the Latin American region has witnessed by far the largest progress in the GDR compared to other regions, a large part of this progress should be considered as catching up to prevalent levels in the developing world from low initial levels. Section 5 discusses this issue more in depth.

\section{Changing Shapes and Slopes: The Grade Enrollment Distribution in Latin America in Comparative Perspective}

What does the picture of progress in Latin American countries look like if we take the entire grade distribution into account and not just the GDR 1-6? How did the shape of the distribution curve change over time and can we discern common patterns? This section provides a detailed comparative analysis of seven Latin American, three Asian and two African countries. The countries are Argentina, Brazil, Chile, Colombia, Mexico, Peru and Venezuela, and Kenya, Egypt, India, South Korea and Malaysia. The five non-Latin American countries are selected because they all reveal some specific distributive aspects that place the Latin American countries in perspective. Figure 2 presents the grade distribution curves ( 3 year moving averages) of the 12 countries in 1960 and 2000 (1990 for Brazil and India). Let's first focus on the shapes of these curves.

There appears to be a great mutual similarity in the shape of Latin American curves in 1960. By and large these curves are convex indicating that the grade distribution is highly skewed in the lower grades, but tends to flatten out in secondary education. In other words, the big watershed takes place in primary education. Once children have reached secondary 
education their relative chances to finish it are much better. Argentina is the single exception to this pattern in 1960. Most benchmark countries reveal an inverted S shape curve pointing out a larger relative emphasis on, or at least a larger relative success in, supporting children on their path towards primary school completion. Only the Indian distribution curve more or less resembles the Latin countries, however with a less pronounced convexity.
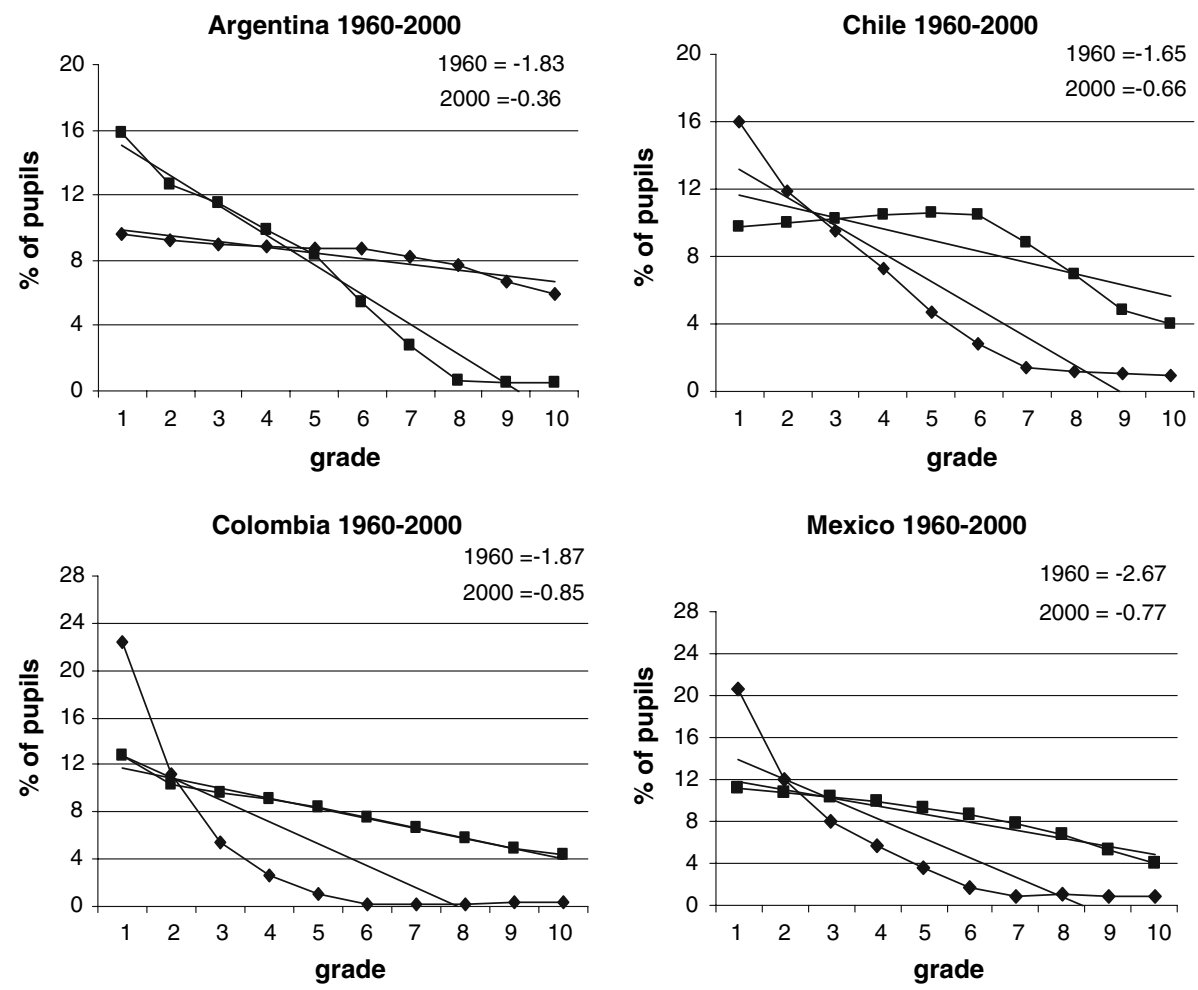

Mexico 1960-2000

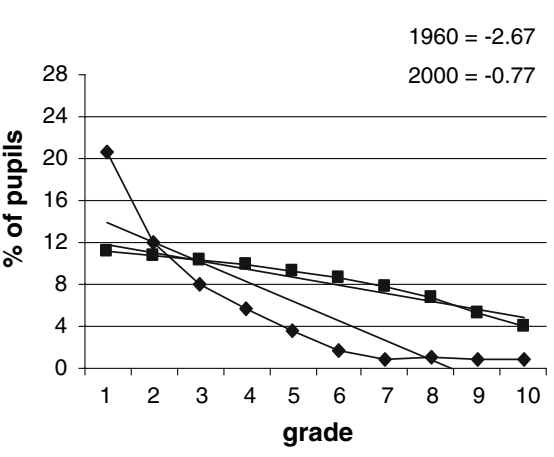

Peru 1960-2000

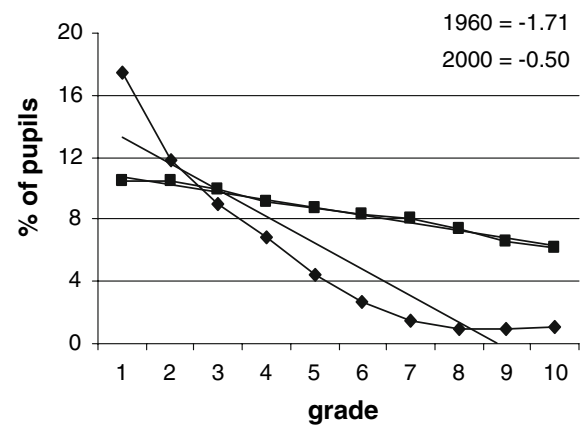

Brazil 1960-1990

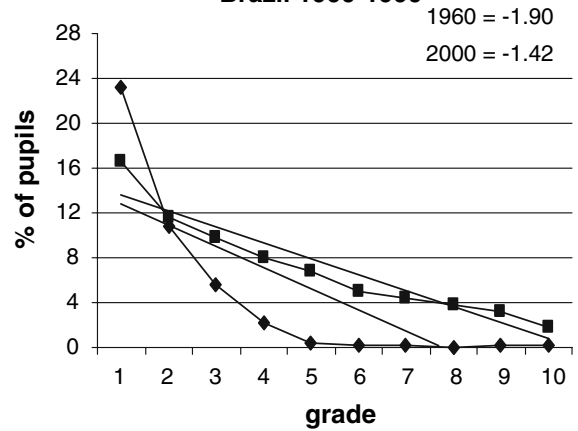

Fig. 2 The grade enrollment distribution in primary and secondary schooling, Latin America versus a selection of non-Latin American countries, 1960-2000. Sources: Authors own calculations based on UNESCO, Statistical Yearbook, 1966-1998 and UNESCO Institute for Statistics (UIS); htttp:// www.uis.unseco.org 
Venezuela 1960-2000

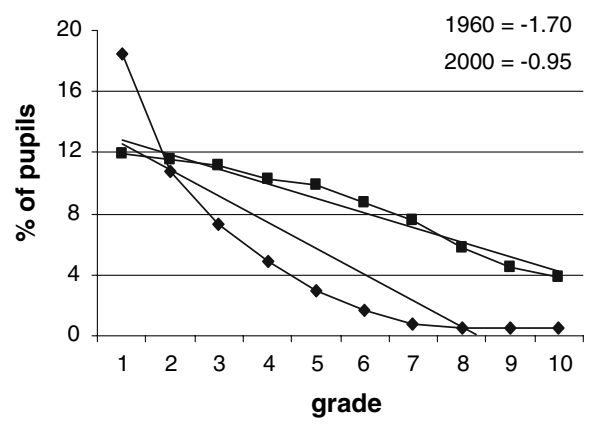

Korea, Rep.1960-2000

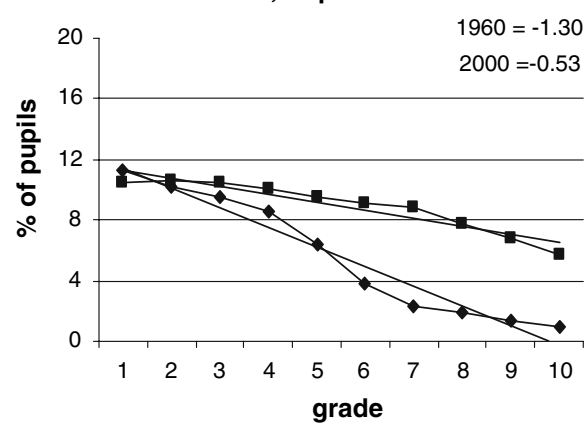

Egypt 1960-2000

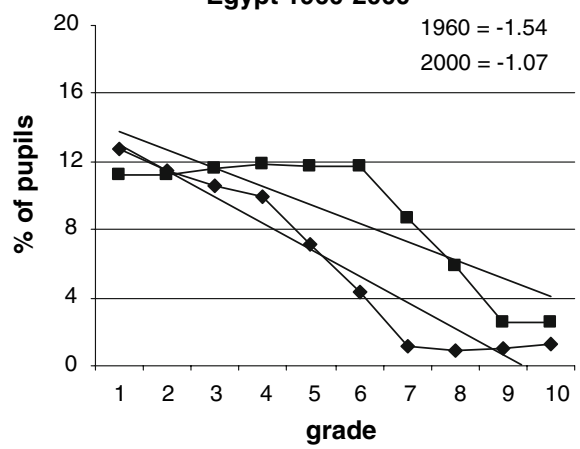

India 1960-1990

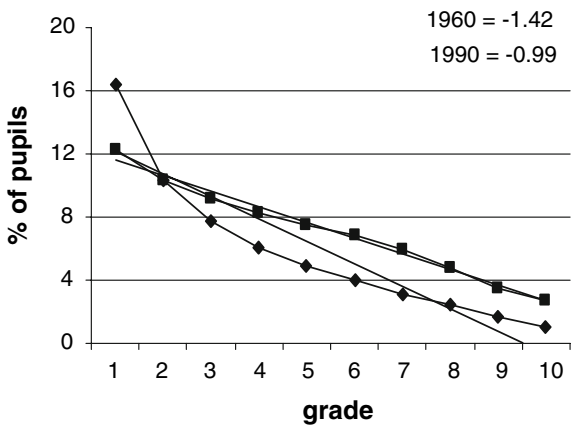

Malaysia 1960-2000

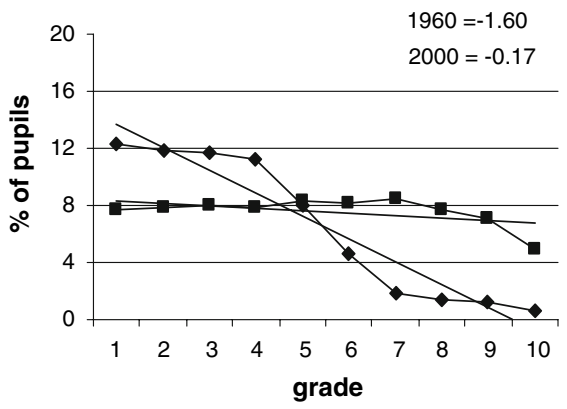

Kenya 1960-2000

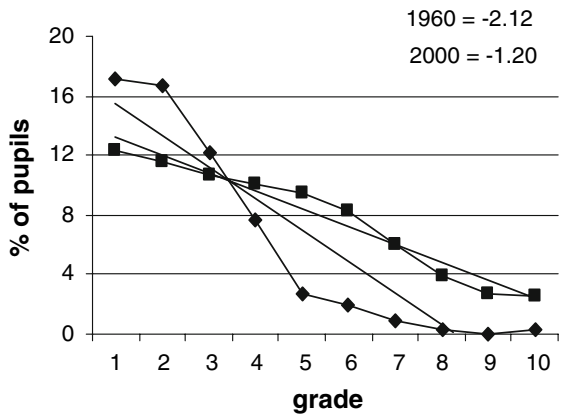

Fig. 2 continued

Towards the 21st century the inverted S shape curve in Egypt and Kenya has largely remained the same, while the distribution as a whole has become considerably more equal. Chile reveals a shift away from convexity towards an inverted S. The other Latin countries seem to follow the pattern best exemplified by Peru: the convex curve gradually transformed into a more or less linear shape, indicating that the grade distribution is still highly skewed towards the lowest grades, yet the skewedness has become less pronounced in the past four decades. Finally, in South Korea and Malaysia the original inverted S curve has moved towards a more linear shape, approaching the horizontal line that indicates a perfectly equal distribution. 
An average linear trend line has been estimated to determine their gradient of the distribution curves. The inference is that steeper downward slopes signal more skewed grade distributions and higher levels of educational inequality. The slopes are reported in the upper right hand corner of each graph for 1960 and 2000 (or 1990). Judged by the changes in the slope of the distribution the progress in five of the seven Latin countries can be considered above average. Argentina, Chile, Colombia, Mexico and Peru all have witnessed a sharp drop in the slope. Mexico stands out with a spectacular drop from -2.67 to -0.77 , but also Argentina and Peru have made respectable progress from -1.83 to 0.36 and -1.71 to -0.50 respectively. Compared to, for example South Korea $(-1.30$ to 0.53 ), this progress can be regarded as substantial "catching up". The performance of Malaysia ( -1.60 to -0.17$)$ surpasses most Latin American countries, save Mexico. Among the Latin countries Venezuela has lagged somewhat behind, while in Brazil progress has been relatively poor (even taking notice of the end year 1990). The slope of the Brazilian curve compares well with those of India and Egypt. Kenya has done comparatively well and now obtains a more equal grade distribution than Brazil. In Kenya, as in Egypt, grade promotion in primary education seems to receive a higher priority than enrollment into secondary education compared to the Latin American countries.

Overall it cannot be concluded that countries with initially high levels of educational inequality have revealed slower progress, on the contrary. In this confined sample of countries a process of convergence between countries in the shapes and slopes of the grade enrollment distribution curve can be observed. Obviously, part of this process is determined by the fact that the initially advanced countries were facing the natural boundary of the grade distribution in an earlier stage. The distinction between the inverted $\mathrm{S}$ curves and the linear distribution curves signals a persistent difference in emphasis on primary versus secondary education however. In Brazil, Venezuela and Mexico the grade distribution is still considerably biased towards lower grades in primary schools. Argentina, Chile and Peru form, by now, the most egalitarian group in the Latin American sample.

Although progress over time is clearly visible in all of the countries under consideration, it should be noted that the labor force of today still contains most of the children that were enrolled in one of those overcrowded primary schools where irregular school attendance, high repetition rates and pre-completion drop out rates were the norm rather than the exception. The reduction of educational inequality requires endurance.

\section{Conclusion}

In this paper it is argued that the grade enrollment distribution approach fills an important gap in the analysis of educational inequality of developing countries. Grade enrollment data not only provide valuable information on the distributive characteristics and effectiveness of national educational systems, they also allow for the construction of a relatively simple and straightforward standardized indicator of educational inequality, i.e., the GDR, that can be traced back at least until the early post-war years.

The GDR signals the effects of irregular attendance and absenteeism on the rates of grade repetition and pre-completion drop out. When adjusted for the impact of demographic change, the GDR (in various possible specifications) expresses the level of inequality incurred by grade repetition and pre-completion drop out rates. A comparison of GDR's across developing countries and over time, complemented by a more detailed comparative analysis of the shape and slopes of the grade distribution curve in Latin American countries, has delivered some interesting results. 
First, there has been a strong wide spread tendency towards equalization of grade enrollment rates throughout the developing world. However, progress has slowed down in the last decades between 1980 and 2005. Several countries, such as Indonesia, Afghanistan and Iraq have witnessed a severe set back and others such as India and Egypt have been moving forward at reduced speed. In Sub Saharan Africa the set back since the 1980s is wide spread, although there are countries, such as Kenya, that have moved on. The majority of Latin American countries do not fit very well into this broad pattern just described. Starting out with staggering low initial levels of the GDR 1-6, all the more remarkable considering the relative advanced position in school enrollment rates in the early post war period, the Latin countries rapidly caught up in the past four decades. This deviating pattern is the result of an initial priority placing "enrollment over attendance".

The analysis of the shapes and slopes of the entire grade enrollment distribution further support this conclusion. In most Latin American countries the initial distribution curves were highly convex, in most non-Latin American developing countries an inverted S shape was the rule. These differences reflect the relative importance of grade promotion and school completion in primary versus secondary schooling and their distributive consequences. Convex curves indicate that children, once enrolled in secondary education, have a relatively large chance to proceed than their counterparts in primary school. The inverted $\mathrm{S}$ shape points out that the relative chances of grade promotion and school completion in primary schools are better. Although Latin American countries have rapidly caught up with prevalent levels of the GDR 1-6 in other developing regions, the shape of the entire distribution curve still reflects present-days problems of high educational inequality.

Acknowledgments I am particularly grateful to Jutta Bolt, co-author of a previous study on this topic, who has greatly contributed to the methods and views developed in this article. I would further like to thank Jan Pieter Smits, Bart van Ark, Marcel Timmer, Lammert Jan Dam, Dirk Bezemer, Henri de Groot, Alan Taylor, the participants of the 2004 NAKE course, Empirics of economic growth, the 2004 Workshop on Welfare Effects of Economic Growth and Standard of Living, Groningen and the 2005 SOM PhD-conference, Groningen, and an anonymous referee, for their valuable comments on previous drafts. The author also acknowledges generous support from the Dutch Science Foundation.

Open Access This article is distributed under the terms of the Creative Commons Attribution Noncommercial License which permits any noncommercial use, distribution, and reproduction in any medium, provided the original author(s) and source are credited.

\section{Appendix}

Table A1 Grade distribution ratio's (1-6) in the developing world, 1960-2005

\begin{tabular}{|c|c|c|c|c|c|}
\hline & \multicolumn{5}{|l|}{ GDR 1-6 } \\
\hline & $1960 / 1965$ & $1970 / 1975$ & $1980 / 1985$ & $1990 / 1995$ & $2000 / 2005$ \\
\hline Afghanistan & 0.46 & 0.60 & 0.67 & 0.66 & 0.34 \\
\hline Bahrain & 0.43 & 0.97 & 0.91 & 0.94 & 0.92 \\
\hline Bangladesh & 0.32 & 0.39 & 0.39 & 0.49 & 0.70 \\
\hline India & 0.42 & 0.50 & 0.54 & 0.67 & 0.72 \\
\hline Iran & 0.67 & 0.66 & 0.71 & 0.98 & 1.00 \\
\hline Myanmar (Burma) & & 0.40 & 0.43 & & 0.66 \\
\hline
\end{tabular}


Table A1 continued

\begin{tabular}{|c|c|c|c|c|c|}
\hline & \multicolumn{5}{|l|}{ GDR 1-6 } \\
\hline & $1960 / 1965$ & $1970 / 1975$ & $1980 / 1985$ & 1990/1995 & $2000 / 2005$ \\
\hline Nepal & 0.28 & 0.32 & 0.46 & 0.44 & 0.47 \\
\hline Pakistan & 0.26 & 0.63 & 0.54 & & 0.58 \\
\hline Sri Lanka & & 0.79 & 0.96 & 1.00 & 1.00 \\
\hline South \& West Asia & 0.40 & 0.59 & 0.62 & 0.74 & 0.71 \\
\hline Hong Kong & 0.69 & 0.88 & 0.96 & 1.00 & 1.00 \\
\hline Indonesia & 0.49 & 0.55 & 0.56 & 1.00 & 0.87 \\
\hline Korea, Rep. & 0.73 & 0.92 & 0.94 & 1.00 & 0.98 \\
\hline Laos & 0.29 & 0.33 & 0.36 & 0.37 & 0.51 \\
\hline Malaysia & 0.82 & 0.81 & 0.94 & 0.89 & 0.96 \\
\hline Mongolia & & 0.78 & 0.32 & 0.68 & 0.83 \\
\hline Papua New Guinea & 0.30 & & 0.67 & 0.65 & 0.61 \\
\hline Philippines & 0.59 & 0.69 & 0.79 & 0.71 & 0.81 \\
\hline Singapore & 0.91 & 1.00 & 1.00 & 1.00 & \\
\hline Thailand & 0.36 & 0.43 & 0.77 & 1.00 & 0.98 \\
\hline Vietnam & 0.34 & 0.45 & 0.73 & & 0.91 \\
\hline East Asia \& Pacific & 0.55 & 0.69 & 0.73 & 0.83 & 0.85 \\
\hline Argentina & 0.63 & 0.70 & 0.75 & 0.83 & 0.92 \\
\hline Barbados & 0.82 & 0.87 & 1.00 & & 1.00 \\
\hline Bolivia & 0.32 & 0.44 & 0.47 & 0.63 & 0.83 \\
\hline Brazil & 0.17 & 0.35 & 0.45 & 0.50 & 0.84 \\
\hline Chile & 0.49 & 0.69 & 0.86 & 0.86 & 1.00 \\
\hline Colombia & 0.20 & 0.37 & 0.56 & 0.70 & 0.74 \\
\hline Costa Rica & 0.41 & 0.68 & 0.85 & 0.79 & 0.90 \\
\hline Cuba & 0.34 & 0.54 & 0.98 & 0.99 & 1.00 \\
\hline Dominican republic & 0.24 & 0.34 & 0.49 & & 0.72 \\
\hline Ecuador & 0.35 & 0.54 & 0.64 & 0.71 & 0.81 \\
\hline El Salvador & 0.29 & 0.46 & 0.54 & 0.67 & 0.70 \\
\hline Guatemala & 0.26 & 0.33 & 0.39 & & 0.49 \\
\hline Guyana & 0.84 & 1.00 & 0.92 & 0.87 & 0.90 \\
\hline Honduras & 0.20 & 0.33 & 0.39 & 0.56 & 0.61 \\
\hline Jamaica & & 0.69 & 0.92 & 0.96 & 0.94 \\
\hline Mexico & 0.32 & 0.52 & 0.64 & 0.82 & 0.88 \\
\hline Nicaragua & 0.18 & 0.35 & 0.32 & 0.41 & 0.59 \\
\hline Panama & 0.57 & 0.59 & 0.79 & 0.80 & 0.83 \\
\hline Paraguay & 0.31 & 0.43 & 0.52 & 0.64 & 0.82 \\
\hline Peru & 0.43 & 0.56 & 0.71 & 0.64 & 0.87 \\
\hline Trinidad \& Tobago & 0.83 & 0.87 & 0.93 & 1.00 & 1.00 \\
\hline Uruguay & 0.58 & 0.79 & 0.82 & 0.85 & 0.83 \\
\hline Venezuela & 0.33 & 0.65 & 0.72 & 0.73 & 0.86 \\
\hline Latin America & 0.41 & 0.57 & 0.68 & 0.75 & 0.83 \\
\hline Angola & & 0.20 & 0.26 & 0.33 & \\
\hline Benin & 0.55 & 0.64 & 0.64 & & 0.57 \\
\hline
\end{tabular}


Table A1 continued

\begin{tabular}{|c|c|c|c|c|c|}
\hline & \multicolumn{5}{|l|}{ GDR 1-6 } \\
\hline & 1960/1965 & 1970/1975 & 1980/1985 & 1990/1995 & $2000 / 2005$ \\
\hline Botswana & 0.55 & 1.00 & 0.80 & 0.98 & 0.94 \\
\hline Burkina Faso & 0.55 & 0.67 & 0.61 & 0.74 & 0.71 \\
\hline Burundi & & 0.52 & 0.71 & 0.89 & 0.60 \\
\hline Cameroon & & 0.55 & 0.63 & 0.70 & 0.76 \\
\hline Central African Republic & 0.31 & 0.45 & 0.58 & 0.52 & \\
\hline Chad & 0.24 & 0.42 & & 0.37 & 0.42 \\
\hline Congo, Dem. Rep. & & 0.45 & & 0.64 & 0.64 \\
\hline Congo, Rep. & 0.39 & 0.66 & 0.75 & 0.69 & 0.68 \\
\hline Ethiopia & 0.30 & 0.53 & 0.34 & 0.39 & 0.42 \\
\hline Gabon & 0.40 & 0.49 & 0.49 & 0.55 & 0.63 \\
\hline Gambia, The & 0.53 & 1.00 & 0.72 & 0.72 & 0.67 \\
\hline Ghana & 0.69 & 0.79 & 0.77 & 0.77 & 0.80 \\
\hline Guinea & & 0.60 & 0.68 & 0.55 & 0.68 \\
\hline Ivory coast & 0.38 & 0.74 & 0.83 & 0.75 & 0.79 \\
\hline Kenya & 0.48 & 0.66 & 0.65 & 0.80 & 0.81 \\
\hline Lesotho & 0.43 & 0.59 & 0.51 & 0.72 & 0.61 \\
\hline Madagascar & 0.31 & 0.35 & 0.51 & 0.35 & 0.31 \\
\hline Malawi & & 0.43 & 0.43 & 0.36 & 0.48 \\
\hline Mali & 0.56 & 0.52 & & 0.52 & 0.63 \\
\hline Mauritania & 0.87 & 0.48 & 0.83 & 0.72 & 0.69 \\
\hline Mauritius & 0.80 & 0.82 & 0.94 & 1.00 & 1.00 \\
\hline Niger & 0.35 & 0.59 & 0.80 & 0.84 & 0.64 \\
\hline Nigeria & 0.53 & 0.48 & 0.80 & 0.79 & 0.75 \\
\hline Rwanda & 0.19 & 0.48 & 0.60 & 0.57 & 0.37 \\
\hline Senegal & 0.53 & 0.84 & 0.79 & 0.77 & 0.71 \\
\hline Sudan & & 0.56 & 0.72 & 0.77 & 0.81 \\
\hline Swaziland & & 0.64 & 0.65 & 0.74 & 0.78 \\
\hline Tanzania & & 0.61 & 1.00 & 0.84 & 0.79 \\
\hline Togo & & 0.52 & 0.61 & 0.52 & 0.66 \\
\hline Uganda & 0.68 & 0.71 & 0.61 & 0.58 & 0.57 \\
\hline Zambia & 0.58 & 0.70 & 0.83 & 0.87 & 0.80 \\
\hline Zimbabwe & & 0.70 & 0.49 & 0.85 & 0.85 \\
\hline Sub Saharan Africa & 0.49 & 0.60 & 0.66 & 0.67 & 0.68 \\
\hline Algeria & & 0.66 & 0.90 & 0.85 & 1.00 \\
\hline Cyprus & 0.87 & 1.00 & 1.00 & 1.00 & 1.00 \\
\hline Egypt & 0.75 & 0.80 & 0.82 & & 1.00 \\
\hline Iraq & 0.49 & 0.72 & 0.75 & 0.84 & 0.72 \\
\hline Israel & 0.96 & 1.00 & 0.95 & 1.00 & 0.96 \\
\hline Jordan & 0.81 & 0.72 & 1.00 & 1.00 & 0.96 \\
\hline Kuwait & 0.49 & 0.97 & 0.60 & 0.93 & 1.00 \\
\hline Libya & 0.44 & 0.51 & 0.87 & & 1.00 \\
\hline Morocco & 0.83 & 0.68 & 0.70 & 0.72 & 0.84 \\
\hline
\end{tabular}


Table A1 continued

\begin{tabular}{llllll}
\hline \multicolumn{7}{l}{ GDR 1-6 } & & & \\
\cline { 2 - 6 } & $1960 / 1965$ & $1970 / 1975$ & $1980 / 1985$ & $1990 / 1995$ & $2000 / 2005$ \\
\hline Oman & & & 0.69 & 0.96 & 0.92 \\
Qatar & 0.18 & 0.67 & 0.85 & 0.92 & 0.90 \\
Saudi Arabia & 0.39 & 0.64 & 0.67 & 0.82 & 0.86 \\
Syria & 0.61 & 0.66 & 0.75 & 0.83 & 0.86 \\
Tunisia & 0.54 & 0.80 & 0.81 & 0.89 & 1.00 \\
Turkey & 0.45 & 0.71 & 0.76 & 0.95 & 0.95 \\
N. Africa \& Middle East & 0.60 & 0.75 & 0.81 & 0.90 & 0.93 \\
Developing world average & 0.49 & 0.62 & 0.70 & 0.75 & 0.78 \\
\hline
\end{tabular}

Sources: Authors own calculations based on UNESCO, Statistical Yearbook, 1966-1998 and UNESCO, Institute for Statistics (UIS); http://www.uis.unseco.org

Notes: For each country the first available observation in the first 5 years of the decade is included; for 60 countries there is at least one observation each decade; countries with less than three observations in five decades, for example South Africa, Bhutan, Mozambique and Haiti, were removed; in some cases the year of observation of the percentage distribution and the total number of students enrolled does not match. A maximum of 2 years difference was allowed. The enrollment figures of primary and secondary schooling always refer to the same year; in a few cases the number of students enrolled in secondary education was derived by the interpolation of two surrounding years; the three standard categories of secondary schooling reported in the yearbook consist of general secondary education, vocational education and teacher training. General secondary education accounts for the bulk of all students and is regularly reported, occasionally figures for teacher training or vocational education are missing. These were estimated with a percentage share obtained from the closest year with full observations. In some countries the number of secondary school students in the early post-war years was almost nihil. For example, The Central African Republic in 1970 reported a total number of 457 students enrolled in secondary school; for total enrollment numbers in primary schooling interpolation methods were not allowed; a few observations were removed because they were suspect and likely to be caused by either typing or reporting errors

\section{References}

Barro, R. J., \& Lee, J. W. (1993). International comparisons of educational attainment. NBER Working Paper No. 4349.

Barro, R. J., \& Lee, J. W. (2001). International data on educational attainment: Updates and implications. Oxford Economic Papers, 53, 541-563.

Birdsall, N. (1999). Education: The people's asset. The Brookings Institution Center on Social and Economic Dynamics, Working Paper No. 5.

Birdsall, N., \& Sabot, R. H. (1994). Inequality, exports, and human capital in East Asia: Lessons for Latin America. In C. Bradford Jr. (Ed.), Redefining the state in Latin America. Paris: OECD Development Centre and Inter-American Development Bank.

Birdsall, N., Ross, D., \& Sabot, R. (1997). Education, growth and inequality. In N. Birdsall \& F. Jaspersen (Eds.), Pathways to growth. Comparing East Asia and Latin America. Washington: Inter-American Development Bank.

Castello, A., \& Domenech, R. (2002). Human capital inequality and economic growth: Some new evidence. Economic Journal, 112, 187-200.

Clemens, M. A. (2004). The long walk to school: International education goals in historical perspective. Center for Global Development, Working Paper No. 37.

Frankema, E. H. P., \& Bolt, J. (2006) Measuring and analysing educational inequality: The distribution of grade enrolment rates in Latin America and Sub-Saharan Africa. Groningen Growth and Development Centre, Research Memorandum, GD-86. Retrieved from http://www.irs.ub.rug.nl/ppn/293057524 
Lindert, P. H. (2004). Growing public. Social spending and economic growth since the 18th century, Vol. 1. Cambridge, MA: Cambridge University Press.

Nehru, V., Swanson, E., \& Dubey, A. (1995). A new database on human capital stock in developing countries and industrial countries: Sources, methodology, and results. Journal of Development Economics, 46, 379-401.

OECD. (2001). Knowledge and skills for life: First results from the OECD programme for international student assessment (PISA) 2000. Paris: OECD.

OECD. (2004). Learning for tomorrow's world: First results from PISA 2003. Paris: OECD.

OECD. (2006). Assessing scientific, reading and mathematical literacy: A framework for PISA 2006. Paris: OECD.

Park, Y. B., Ross, D., \& Sabot, R. H. (1996). Educational expansion and the inequality of pay in Brazil, Korea. In N. Birdsall \& R. H. Sabot (Eds.), Opportunity forgone: Education in Brazil. Washington: Inter-American Development Bank, Johns Hopkins University Press.

Psacharopoulos, G. \& Arriagada, A. (1986). The educational attainment of the labour force: An international comparison. Washington: World Bank Report EDT38.

Ram, R. (1990). Educational expansion and schooling inequality: International evidence and some implications. The Review of Economics and Statistics, 72, 266-274.

Sahn, D., \& Younger, S. (2004). Changes in inequality and poverty in Latin America: Looking beyond income to health and education. Cornell Food and Nutrition Policy Program Working Paper, No. 165.

Thomas, V, Wang, Y., \& Fan, X. (2001). Measuring education inequality: Gini coefficients of education. Policy Research Working Paper 2525. Washington: World Bank.

UNESCO. (1958). World survey of education II. Primary education. Zürich: UNESCO.

UNESCO. (1966-1988). Statistical yearbook. Geneva: UNESCO.

UNESCO. Institute for statistics (UIS). Geneva: UNESCO. Retrieved from http://www.uis.unesco.org

UN. World population prospects: The 2004 revision population database. New York: UN. Retrieved from http://www.esa.un.org/unpp/

World Bank. (1993). The East Asian miracle. Economic growth and public policy. World Bank Policy Research Report. Oxford University Press. 